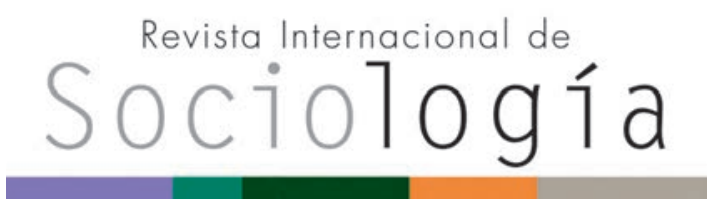

Revista Internacional de Sociología RIS

vol. 76 (2), e090, abril-junio, 2018, ISSN-L:0034-9712

https://doi.org/10.3989/ris.2018.76.2.16.01630

\title{
MAX WEBER Y LA DEMOCRACIA PLEBISCITARIA
}

\author{
MAX WEBER AND THE \\ PLEBESCITARIAN DEMOCRACY
}

\author{
MARIO D. SERRAFERo \\ Universidad de Buenos Aires \\ mserrafero@gmail.com \\ ORCID iD: https://orcid.org/0000-0002-9783-6562
}

Cómo citar este artículo / Citation: Serrafero, M. D. 2018. "Max Weber y la Democracia Plebiscitaria". Revista Internacional de Sociología 76(2):e090. https://doi. org/10.3989/ris.2018.76.2.16.01630

\begin{abstract}
REsumen
En este trabajo se desarrollan las ideas de Weber en relación a la llamada "democracia plebiscitaria". En primer lugar, se describen sus ideas sobre la democracia parlamentaria y la democracia plebiscitaria señalando sus particularidades y diferencias. Luego se aborda específicamente la democracia plebiscitaria como un tipo de dominación carismática. En el estudio se trata tanto el análisis científico que realiza Weber sobre la democracia plebiscitaria como también su propuesta política para un momento específico de la historia de Alemania, la primera posguerra. En el trabajo se señalan los límites teóricos de la propuesta de democracia plebiscitaria desde la propia teoría de Weber. El estudio revaloriza el análisis de Weber sobre una democracia que parece tener cada vez más vigencia.
\end{abstract}

\section{Palabras Clave}

Democracia; Liderazgo; Liderazgo carismático.
Copyright: (c) 2018 CSIC. Este es un artículo de acceso abierto distribuido bajo los términos de la licencia de uso y distribución Creative Commons Reconocimiento 4.0 Internacional (CC BY 4.0).

Recibido: 10/11/2016. Aceptado: 15/11/2017.

\section{Abstract}

This paper deals with Weber's ideas in relation to the so-called 'plebiscitary democracy'. Firstly, it describes his ideas on parliamentary democracy and plebiscitary democracy, documenting their particularities and differences. Secondly, it specifically addresses the plebiscitary democracy as a kind of charismatic domination. The study analyses both Weber scientific analysis on plebiscitary democracy as the political proposal for a specific time in the history of Germany, early into the post-war period. This paper highlights the theoretical limits of the proposed plebiscitary democracy from Weber's own theory. The study also revalues and revisits Weber's analysis of a kind democracy that seems to be increasingly present in current political times.

\section{KEYWORDS}

Charismatic Leadership; Democracy; Leadership. 


\section{INTRODUCCIÓN}

¿Democracia parlamentaria o democracia plebiscitaria? Disyuntiva que dejó Weber, al sostener por un lado la defensa de la democracia parlamentaria $y$, por el otro, proponer una democracia plebiscitaria para la Alemania de la primera posguerra. Según Eliaeson (1991), Weber solo puede ser entendido desde el contexto de la experiencia alemana. Estas dos formas de gobierno fueron sostenidas por Weber en sus escritos. El primer esquema tenía al Parlamento como órgano central y al parlamentarismo como sistema; el segundo, la emergencia de una democracia de tipo plebiscitaria, de contenido más emotivo y con el presidente como núcleo del sistema. Destacar esta ambivalencia es importante por varias razones: a) significa definiciones muy diferentes sobre aspectos esenciales de una democracia: su legitimidad, su eficacia y su estabilidad, b) significa optar por una versión más o menos liberal, en el sentido político del concepto, y c) dentro de las concepciones de Weber podría suponerse que la elección de determinada forma institucional debería completar su teoría de la dominación legal o racional. En este sentido, aunque sea discutible, Raymond Aron (1965:136 y 137) señaló que el pensamiento político de Weber no es sistemático, principalmente, en cuanto a las "formas de gobierno" y Karl Loewenstein (1982:536) afirmó que el maestro dejó incompleta su teoría de la dominación al no incluir la teoría constitucional y las formas institucionales en su dominación de tipo legal.

Las preguntas que se formulan no son pocas: ¿Cuáles son las notas esenciales de los dos formatos de democracia tratados por Weber?, ¿en qué contexto se formulan sus argumentaciones?, ¿cuáles son las justificaciones y las características del tipo de democracia plebiscitaria que plantea? Y más allá del propio Weber, ¿cómo articula la democracia presidencial plebiscitaria con las características de la dominación carismática? ¿Cuáles serían las tensiones que tendría de acuerdo a estas características? ¿Con qué debates se cruza la perspectiva de democracia plebiscitaria en nuestros días?

Este trabajo sostiene que fueron esquemas democráticos diferentes, pero que sin embargo mantenían ciertas coherencias en el pensamiento de Weber en lo atinente a la importancia del líder en el sistema político y democrático, y también, en este punto, se localizaba la tensión máxima de la propuesta plebiscitaria en el conjunto de sus ideas. Profundizar en el contenido de esta ambivalencia es útil, además, para enriquecer los debates sobre la democracia. Asimismo, la democracia plebiscitaria planteada por Weber implicaba un mayor distanciamiento en relación con el modelo predominante de democracia liberal que, de alguna manera, se encontraba más próxima a su exposición del esquema parlamentario. La democracia plebiscitaria desarrollada por Weber resulta una aproximación extraordinariamente rica al haberla encuadrado el autor dentro de la dominación carismática, con todas las consecuencias que de ello derivaban. Y sirve como soporte teórico a desarrollos más recientes que advierten las formas democráticas que se alejan del modelo liberal y que han recibido distintas denominaciones.

En este trabajo el abordaje de la democracia plebiscitaria va más allá de las coordenadas históricas de la situación alemana -entre 1917 y 1919- que explicarían el viraje de Weber desde la democracia parlamentaria a la República presidencialista. Aquí se integran las características específicas de la dominación carismática que desarrolla Weber -en otros textos- y que suelen dejarse un tanto de lado cuando se analizan las causas o contexto histórico del referido viraje. Este modo de tratamiento permite encontrar ciertas continuidades entre los dos esquemas de democracia $\mathrm{y}$, fundamentalmente, las características y las tensiones de la versión plebiscitaria. Este abordaje también vincula discusiones teóricas con los desarrollos de Weber, los cuales no suelen estar presentes en su justa medida a la hora de conceptualizar las características de gran parte de las democracias actuales.

\section{El MARCO de LAS PROPUESTAS de WEBER}

Decía Weber que la creciente intelectualización y racionalización del mundo significaba que las cosas podían ser dominadas por el cálculo y los recursos técnicos. En este proceso de desencantamiento de la cultura occidental la ciencia era su fuerza motora (Weber 1980b:38). Pero la ciencia no debía fundamentar cosmovisiones ni postular convicciones de valor. No podía dar "el" significado de la vida, ni formular ideales, sino explicar los hechos desde la objetividad. El "desencantamiento del mundo" implicaba que ya no había una respuesta única normativa aceptada y aceptable para todos. La ciencia no daba respuestas definitivas sino que estaba en constante búsqueda de la verdad. La lucha por los valores por los que las personas orientaran su vida era entonces inevitable. No era atribución de la ciencia fundamentar valores. (Abellán 2010:47-49).

El proceso de desencantamiento del mundo implicaba la burocratización de todas las esferas de la vida y una amenaza para la libertad individual. Weber temía la excesiva burocratización, en tanto extralimitado avance de la racionalidad formal y del "gobierno de funcionarios". Reconocía que en el moderno Estado de masas, el verdadero dominio, que era el manejo diario de la administración, debía estar necesariamente en manos de la burocracia. Pero en la política, no es el funcionario o burócrata el actor protagónico, sino el político.

Para Weber en la política alemana imperaba el dominio de la burocracia, contra la cual la monar- 
quía era insuficiente en cuanto a su control y dirección. El liderazgo político era la clave para contrapesar este proceso. El verdadero funcionario no debe hacer política, sino que debe administrar imparcialmente, en cambio el político debe tomar una posición. Ser apasionado es el elemento del político y sobre todo del líder (Weber 1980a:92). Su reflexión la inscribe dentro del marco de la política y los valores. Así diferencia entre la ética del funcionario y la ética del político. El funcionario realiza la ejecución precisa y concienzuda de la orden dada por la autoridad superior-como si respondiera a sus propias convicciones y aunque le parezca errónea-, el desempeño del cargo sine ira et studio, la negación de sí mismo y la descarga de toda la responsabilidad en el superior. El político, en cambio, debe obrar de acuerdo a la "ética de la responsabilidad", donde lo importante son los resultados que originan sus actos, la responsabilidad por las consecuencias de su opción valorativa y de la dirección que le imprime al Estado.

Varios hechos conforman un clima de reforma institucional en el cual Weber tendrá una activa participación. Entre estos hechos cabe mencionar la reforma del derecho electoral de Prusia -donde los soldados que defendían la patria no tenían voto igualitario- y la caída del zarismo en Rusia que contribuía a plantear un debate sobre la reforma constitucional en Alemania (Abellán 2004:114). Se creó entonces una Comisión constitucional para preparar la introducción del sistema parlamentario en Alemania. $Y$ son los hechos los que van marcando los cambios en las posiciones de Weber, respecto de la opción entre una democracia parlamentaria y otra plebiscitaria. En el texto Parlamento y Gobierno en el marco de la Monarquía burocrática, la hegemonía de Prusia y la existencia de las dinastías en varios de los Estados Federados, la salida para Weber era la parlamentarización del sistema político como clave para resolver el problema de la necesidad de líderes políticos frente a la dominación burocrática (Abellán 2004:169). Pero la abdicación del emperador a comienzos de noviembre de 1918, marcaba un cambio sustancial de la situación política y una nueva cuestión: la jefatura del Estado y aparece aquí la opción por la democracia presidencialista. El propio Weber reconoce expresamente en La futura forma institucional de Alemania (estudio donde aborda las alternativas futuras y posibles del nuevo ordenamiento alemán que los propios hechos imponían) que su trabajo Parlamento y Gobierno había sido sobrepasado por los acontecimientos. Es en el artículo El presidente del Reich donde Weber argumenta las razones de la necesidad de que el presidente sea electo directamente por el pueblo y completa el perfil de la democracia plebiscitaria. El contexto de esta publicación había sido la elección por la Asamblea Nacional de Friedrich Eber como presidente de la República.

\section{¿DOS ESQUEMAS DE DEMOCRACIA? LA DEMOCRACIA PARLAMENTARIA}

¿Weber propone en definitiva dos formatos democráticos diferentes, o bien una mezcla entre la forma plebiscitaria o parlamentaria? Las referencias mencionadas -y señaladas por el propio Weber- nos muestran dos propuestas diferentes. Aunque también se ha sostenido que, en realidad, se trataba de una propuesta mixta (Parlamento fuerte y presidente elegido directamente por el pueblo) ${ }^{1}$. Parte de la producción escrita del autor se vuelca hacia una democracia parlamentaria, esto es en Economía y Sociedad y en Parlamento y Gobierno en el nuevo ordenamiento alemán. Y un breve trabajo, El presidente del Reich, da silueta a una clara democracia plebiscitaria.

La democracia parlamentaria es una fórmula institucional que tiene al Parlamento como órgano central y el parlamentarismo como sistema. Esta forma de gobierno tiene una vinculación débil con la teoría de la división de poderes, tema abordado por Weber desde una perspectiva del poder concreto y no desde el tecnicismo propiamente jurídico (Weber 1992:227), "aunque las apropiaciones de competencias firmes suelen ser favorables a la racionalización formal" (Weber 1992:228). No obstante, se mantiene la perspectiva de los "contrapesos" desde una visión de la teoría de dominación weberiana. En esta visión, son fenómenos concomitantes de la dominación legal: los procesos de burocratización y de democratización. Para Weber la parlamentarización y la democratización no están en una relación recíproca necesaria, sino que a menudo están en oposición. Históricamente la democratización significó el menor peso de los honoratiores y en la jefatura parlamentaria asumieron protagonismo los preferidos por la masa. Por otra parte, democratización y demagogia suelen ir juntas. En relación a la burocratización, la democratización tiende a aumentarla, por ejemplo con la emergencia de partidos más organizados.

Antes de señalar el modo de obrar como contrabalanza del poder, hay que destacar la función legitimadora del Parlamento como órgano. Para Weber los Parlamentos son el modo en que los dominados manifiestan un mínimo de aprobación externa en relación al sistema de dominación, (Weber 1992:1095) cuyo eje se centra en la burocracia. El Parlamento "activo" de política positiva -que decide en la política y la administración- es contrapeso de la burocracia, en tanto y en cuanto puede controlar (Weber 1992:1099) el saber técnico y de servicio de los burócratas. Para ello el Parlamento debe ser órgano eficaz y activo y requiere la profesionalización de sus miembros (Weber 1992:1103). La política, para Weber, no es cosa de burócratas sino de políticos. El mismo tipo de Parlamento activo, obra también de contrapeso del efecto negativo del proceso de democratización: la demagogia. En este sentido, ocupa un lugar esencial el modo de selección de los jefes. 
La emergencia del jefe a través de la selección que impone la lucha en el ámbito parlamentario (Weber 1992:1099-1103), es el mejor remedio contra el jefe demagógico. La política requiere abandonar los "elementos emocionales" y obrar con mente "clara y fría" (Weber 1992:1117),

Respecto del Parlamento señala que no sólo es el órgano de control de la burocracia, sino el lugar del compromiso entre los partidos. Dice: "En cuanto órgano de control de la burocracia y de la publicidad administrativa, como medio de eliminación de funcionarios superiores incompetentes, como lugar de fijación del presupuesto y como elemento donde puedan lograrse compromisos entre partidos, el parlamento es también en las democracias electivas imprescindible" (Weber 1992:1114).

Bajo la influencia del modelo de Inglaterra reflexiona sobre la monarquía democrática donde existe un Ejecutivo bicéfalo. El Monarca como portador del "carisma rutinizado" no responsable y no sujeto a la prueba de la eficacia de sus actos, el Premier como aquel que sí responde por sus actos ante la asamblea. En este esquema de democracia parlamentaria tradicional la selección parlamentaria presenta ventajas porque garantiza: 1) la continuidad, 2) el control de su posición de poder, 3) el mantenimiento frente a él de las garantías jurídicas burguesas, 4) una forma ordenada de los méritos de los políticos que aspiran a la confianza de las masas en el marco del trabajo parlamentario, y 5) una forma pacífica de eliminación del dictador cesarístico una vez que ha perdido la confianza de las masas (Weber 1992:1110). Incluso la selección parlamentaria tiene la ventaja de suplir el vacío que pudiere existir al no emerger ningún "jefe" que goce de la confianza general de la gente.

En la democracia parlamentaria los hombres de confianza de la masa no están ausentes, pero se produce una suerte de adecuación al tener que participar de las comisiones parlamentarias, lo que permite que "se adapten a las firmes formas jurídicas de la vida del Estado y no se les elija de modo simplemente emocional, o sea, por sus meras cualidades 'demagógicas' en el sentido peyorativo del vocablo". (Weber 1992:1116). Agrega que: "Precisamente en las condiciones actuales de selección de los jefes, constituyen un Parlamento fuerte y unos partidos parlamentarios responsables, en cuanto lugar de selección y prueba de los conductores de masas para los directivos del Estado, factores fundamentales de una política estable" (Weber 1992:1116).

Los elementos constitutivos y funcionales de esta democracia parlamentaria, en apretada síntesis serían: la legitimidad del sistema ubicada en el Parlamento, su eficacia en la selección de los líderes en la arena parlamentaria, el control de burocracia y la negociación entre los partidos, la estabilidad garantizada a través de la sucesión que produce el juego parlamentario. Los actores políticos que tejen el juego institucional son: los partidos políticos fuertes con representación parlamentaria y un Parlamento activo y vigoroso. En este cuadro los actores relegados son la "masa del pueblo" y la burocracia que se pretende controlar.

\section{SOBRE LA CUESTIÓN CARISMÁTICA}

Antes de tratar específicamente la democracia plebiscitaria es pertinente referirse brevemente a la cuestión carismática. Weber trata y diferencia distintos tipos de legitimidades, la tradicional, la formallegal y la carismática. Decía respecto de esta última: “Debe entenderse por 'carisma' la cualidad, que pasa por extraordinaria (condicionada mágicamente en su origen, lo mismo si se trata de profetas que de hechiceros, árbitros, jefes de cacería o caudillos militares), de una personalidad, por cuya virtud se la considera en posesión de fuerzas sobrenaturales o sobrehumanas -o por lo menos específicamente extracotidianas y no asequibles a cualquier otro-, o como enviado del dios, o como ejemplar y, en consecuencia, como jefe, caudillo, guía o líder. El modo como habría de valorarse 'objetivamente' la cualidad en cuestión, sea desde un punto de vista ético, estético u otro cualquiera, es cosa del todo indiferente en lo que atañe a nuestro concepto. Pues lo que importa es cómo se valora 'por los dominados' carismáticos, por los 'adeptos'” (Weber 1992:193),

El carisma refiere al reconocimiento de las cualidades extraordinarias que los seguidores le atribuyen al jefe o al héroe y que implica una entrega plena. En palabras de Weber: "Sobre la validez del carisma decide el reconocimiento -nacido de la entrega a la revelación, de la reverencia por el héroe, de la confianza en el jefe -por parte de los dominados, reconocimiento que se mantiene por 'corroboración' de las supuestas cualidades carismáticas - siempre originadas por medio del prodigio. Ahora bien, el reconocimiento (en el carisma genuino) no es el fundamento de su legitimidad, sino un deber de los llamados, en méritos de la vocación y de la corroboración, a reconocer esa cualidad. Este 'reconocimiento' es psicológicamente, una entrega plenamente personal y llena de fe surgida del entusiasmo o de la indigencia y la esperanza" (Weber 1992:194).

El líder carismático logra la confianza de sus seguidores que le atribuyen cualidades extraordinarias. Pero si no se corrobora la permanencia de estas cualidades traducidas, especialmente, en el bienestar de los seguidores el carisma puede perderse. En palabras de Weber: "Si falta de un modo permanente la corroboración, si el agraciado carismático parece abandonado de su dios o de su fuerza mágica o heroica, le falla el éxito de un modo duradero y, sobre todo, si su jefatura no aporta ningún bienestar a los dominados, entonces hay la probabilidad de que su autoridad carismática se disipe. Este es el sentido 
genuinamente carismático del imperio 'por la gracia de dios'" (Weber 1992:194).

Singularmente importante es el panorama político e institucional que se entreteje alrededor del líder carismático y que va conformando las características del régimen político que se instaura. En este régimen no habrá cuadro administrativo que obedezca a una estructura racional-formal, sino funcionarios obedientes al líder. No habrá magistrados ni competencias, no habrá ley ni reglamentaciones abstractas, sino órdenes fundadas en la revelación creída en base a la autoridad carismática. Expresa Weber: "El cuadro administrativo de los imperantes carismáticos no es ninguna 'burocracia', y menos que nada una burocracia profesional...es elegido a su vez por cualidades carismáticas: al profeta corresponden los discípulos, al príncipe de guerra el 'séquito' al jefe, en general, 'Ios hombres de confianza'. No hay ninguna colocación ni destitución, ninguna carrera ni ascenso sino sólo llamamiento por el señor según su propia inspiración fundada en la calificación carismática... no existen ni 'jurisdicción' ni 'competencias'... No hay ninguna 'magistratura' firmemente establecida... No existe reglamento alguno, preceptos jurídicos abstractos, ni aplicación racional del derecho" (Weber 1992:194-195).

La democracia plebiscitaria formaba parte de la dominación carismática, pero podía tener distintos desplazamientos. Así, en relación con la economía dice que la transformación antiautoritaria del carisma conduce por lo general a la ruta de la racionalidad. El apoyo en una burocracia eficiente y la destrucción de poderes tradicionales, feudales, patrimoniales para vincular los poderes económicos a un nuevo orden puede facilitar la formalización del derecho y fomentar una economía formalmente racional.

Pero otro desplazamiento iría en dirección contraria y podría llegar a instaurar una dictadura social. Dice Weber, "Los poderes plebiscitarios pueden ser fácilmente debilitadores de la racionalidad (formal) de la economía si la dependencia de su legitimidad de la creencia y entrega de las masas les obliga, al contrario, a mantener, aún en el terreno económico, postulados de justicia de carácter material; o sea, a romper el carácter formal de la justicia y la administración con una justicia (de cadí) de naturaleza material (tribunales revolucionarios, bonos de racionamiento y toda suerte de formas de producción y consumo racionales y controladas). En tal circunstancia se trata de un dictador social, fenómeno que no está necesariamente vinculado a las formas sociales modernas" (Weber 1992:216).

La vinculación entre carisma y economía aparece clara: "El carisma puro es específicamente extraño a la economía...Las formas típicas de la cobertura de necesidades de carácter carismático son, de un lado, las mecenísticas -de gran estilo (donaciones, fundaciones, soborno; propinas de importancia)- y las mendicantes, y, de otro lado, el botín y la extorsión violenta o (formalmente) pacífica. Considerada desde la perspectiva de una economía racional es una fuerza típica de la 'antieconomicidad', pues rechaza toda trabazón con lo cotidiano" (Weber 1992:196). Quizá ésta es una perspectiva extrema -pues habla de carisma puro- que va más allá del caso de la democracia plebiscitaria, pero marca una relación problemática entre dominación carismática y racionalidad económica.

La relación entre carisma y democracia es compleja. La democracia implica una transformación de los procesos carismáticos de la "aclamación”, "designación" o el "plebiscito", con la que se expresaba el reconocimiento al líder, en la elección que legitima al gobernante. Antes, el reconocimiento se refería a las cualidades que tenía el líder. En la democracia, es la elección la que se convierte en fundamento de la legitimidad. Asimismo, la reinterpretación antiautoritaria del carisma (Weber 1992:214) implica la idea de que la voluntad de los dominados es la determinante de la norma válida y el procedimiento es la mayoría que resulta tras el recuento de los votos. La transformación carismática se reinterpreta en un sentido legal, racional. $\mathrm{O}$, en otros términos se produce su racionalización. (Breuer 1996: 198-199; Abellán 2004: 102). ¿Cuándo es compatible el liderazgo carismático con la democracia? Cuando el carisma es rutinizado en dirección a las reglas racionaleslegales. Por otra parte, los regímenes democráticos e incluso los no democráticos se despliegan en una combinación de elementos carismáticos y racionales (Benhardt 1998).

\section{La Democracia Plebiscitaria}

Weber diferenciaba entre la democracia de jefes y la democracia sin jefes, esta última "caracterizada por el esfuerzo por aminorar la dominación de unos hombres sobre otros" (Weber 1992: 215-216). Planteó en diferentes escritos los contornos de la democracia plebiscitaria dentro de la especie de dominación carismática. Señalaba: "La democracia plebiscitaria -el tipo más importante de la democracia de jefes- es, según su sentido genuino, una especie de dominación carismática oculta bajo la forma de una legitimidad derivada de la voluntad de los dominados y sólo por ella perdurable. El jefe (demagogo) domina de hecho en virtud de la devoción y la confianza personal de su séquito político. En primer lugar, sobre los adeptos ganados a su personal, cuando éstos, dentro de la asociación, le procuran la dominación" (Weber 1992:215).

Esta democracia implicaba una dominación carismática bajo la forma de una voluntad derivada de los dominados. La devoción y confianza de aquéllos la hacía posible y sólo perdurable por su voluntad. Cuando Weber ilustra con ejemplos históricos quié- 
nes estarían bajo esta categoría, la lista es amplia, pues engloba dictadores, revolucionarios, demagogos y hasta dictadores o funcionarios municipales, basta que exista un "reconocimiento plebiscitario" del jefe para ingresar en la categoría. Señala: "El tipo lo dan los dictadores de las revoluciones antiguas y modernas; aisymnetas, tiranos y demagogos griegos, en Roma Graco y sus sucesores, en las ciudades italianas los capitani del popolo y burgomaestres (tipo en Alemania: la dictadura democrática de Zurich, en los estados modernos la dictadura de Cromwell, los gobiernos revolucionares y el imperialismo plebiscitario en Francia. Siempre que hubo un intento de legitimar esta forma de gobierno se buscó hacerlo por medio del reconocimiento plebiscitario del pueblo soberano. El personal del cuadro administrativo fue reclutado carismáticamente de entre los plebeyos capaces (con Cromwell considerando su calificación religiosa, con Robespierre teniendo en cuenta ciertas cualidades 'éticas' junto a la confianza personal que inspiraba, con Napoleón por la exclusiva consideración de su capacidad y utilidad para los fines de la imperial 'dominación del genio'. En el punto culminante de la dictadura revolucionaria tiene el carácter de una administración por medio de puros mandatos ocasionales y revocables (así la administración de comisarios en la época del Comité de Salud Pública). Así el dictador municipal, que alcanza gran significación por obra de movimientos de reforma, se hizo conceder el libre nombramiento de sus auxiliares. La dictadura revolucionaria ignora de igual manera tanto la legitimidad tradicional como la legalidad formal" (Weber 1992:215).

Esta democracia tiene un fuerte contenido "emotivo". Dice Weber: "Es característico de la democracia de caudillaje en general el carácter emotivo y espontáneo de la entrega y confianza en el líder, de que suele suceder la inclinación a seguir como tal al que aparece como extraordinario, al que promete más, al que actúa con medios más intensamente atractivos. La traza utópica de todas las revoluciones tiene aquí sus fundamentos naturales. También están aquí los límites de racionalidad de esta administración en la época moderna -pues tampoco en Norteamérica respondió siempre a las esperanzas" (Weber 1992:216). La confianza se deposita en quien se le atribuyen poderes extraordinarios o bien actúa como demagogo o una suerte de ilusionista recurriendo a mecanismos de atracción o seducción. $Y$ en Weber se repite cierta vinculación entre caudillaje, utopía y revolución; y resulta coherente justamente porque al líder se le atribuyen cualidades extraordinarias que pueden, en definitiva, superar o ir más allá del statu quo.

La dominación carismática al exigir la "prueba" de las dotes especiales del líder implica que se deposita un control directamente en manos de los seguidores. Si éstos son defraudados el líder carismático dejará de ser la persona de confianza y hasta podrá producirse su caída. Esto es asimilable a lo que hoy llamaríamos una accountability vertical. Es que los actos del líder carismático tienen consecuencias y serán responsables entonces por el bienestar o no de los seguidores. La elección del líder por el pueblo y su responsabilidad formaban parte de una versión de la democracia expuesta crudamente en conversación con Ludendorff. Le dice Weber: "In a democracy the people choose a leader in whom they trust. Then the chosen leader says, 'Now shut up and obey me'. People and party are then no longer free to interfere in his business. Later the people can sit in judgment. If the leader has made mistakes - to the gallows with him!" (Gerth y Wright Mills 1991:42).

Pero mientras los líderes gozan de tal confianza su posición es distinta a la de un funcionario y, en este plano, gozan de mayor discrecionalidad y se torna más difícil el ejercicio de la accountability horizontal, sobre todo, teniendo en cuenta el marco carismático en que desenvuelven su actuación. Esta característica es muy importante pues remite a un modo de gestión y ejercicio del poder. Weber remarca esta diferencia respecto del funcionario electo y dice: "el funcionario se comportará en todo como mandatario de su señor-aquí, pues, de los electores-, y el caudillo, en cambio, como responsable exclusivamente ante sí mismo, o sea, mientras aspire con éxito a la confianza de aquéllos, actuará por completo según su propio arbitrio (democracia de caudillo) y no, como el funcionario, conforme a la voluntad, expresada o supuesta (en un "mandato imperativo'), de los electores” (Weber 1992:716). Esta diferencia entre la accountability vertical y horizontal no aparece expresamente en Weber, pero puede inferirse de su conceptualización de la dominación carismática y resulta útil para comprender los procesos democráticos actuales.

Cabe traer aquí otro término utilizado por Weber: el cesarismo. Aparece mencionado en varias situaciones y contextos, por ejemplo para referirse al predominio de Bismark. Pero a partir de 1913 deja de tener una connotación cuasidictatorial y refiere a la figura del genio y a cierta conexión con las estructuras democráticas (Breuer 1996:198). Para Weber (1992:721) se basaba principalmente "en la posición ocupada por el 'César' en cuanto hombre de confianza de las masas (del ejército o de los ciudadanos) desligado de toda tradición, en cuanto soberano ilimitado y jefe de un cuadro de oficiales y funcionarios altamente calificados, seleccionados libremente por él sin atender a la tradición o a otras consideraciones. Este 'dominio del genio personal' está, sin embargo, en contradicción con el principio formalmente 'democrático' de la burocracia electiva". Nos encontramos aquí frente a la figura del genio y, según los autores, este cesarismo podía tener distintos signos, así Gramsci (1993) distinguía entre un cesarismo 
progresista representado por ejemplo por César y Napoleón Bonaparte y un cesarismo reaccionario ejemplificado en Napoleón III.

\section{Parlamentarismo: Parlamento, BUROCRACIA Y GOBIERNO}

En Parlamento y Gobierno en el nuevo ordenamiento alemán, Weber realiza reflexiones políticas sobre la situación alemana (Lachmann 1970). Fueron artículos de 1917 publicados la Frankfurter Zeitung; luego, en 1918, son reunidos en la colección Die innere Politik editada por Siegmund Hellmann y otros; y, en 1919, aparece una segunda versión de los mismos, corregida y aumentada por el propio Weber. Expresamente comienza señalando que el ensayo "no pretende acogerse bajo la autoridad protectora de ninguna ciencia". El trabajo combina estudios académicos con opiniones políticas. Muchos pasajes de estos textos aparecen también en la segunda parte de "Economía y sociedad", obra que estaba en proceso de elaboración, aún no editada en aquellos tiempos y sujeta hoy a no pocas controversias (Mommsen 2014).

El estudio pretende defender el sistema parlamentario contra los ataques que recibía en Alemania. Estas opiniones se centran sobre Bismarck y la situación alemana de aquella época. Weber se refiere al legado de Bismark reconociendo su estatura de estadista y de genio político. Pero junto con este reconocimiento, señala que su legado fue un Parlamento impotente e incapaz de dotar de dirección política al país. Señala que "Bismarck no toleró ningún poder autónomo ni en los Ministerios ni el Parlamento. Tampoco permitió la consolidación de partidos políticos fuertes e independientes. Su legado consistió en una nación sin ninguna sofisticación ni tradición políticas y sin una voluntad política propia. Empleó los argumentos monárquicos según sus propios intereses de poder y no aceptó mentes políticamente independientes ni personalidades políticamente fuertes. El Parlamento resultó, por lo tanto, una institución completamente impotente en la cual no sucedían hechos importantes" (Weber 1982b: 74).

El legado Bismarck había sido el predominio de un segmento de burócratas profesionales, con una burocracia civil y militar superiores a los existentes en cualquier país, pero que había impedido la emergencia del talento político. Contra este predominio de los burócratas hacía falta un Parlamento que pudiera desarrollar una política positiva y que controlara a la burocracia. El monarca no podía ejercer tal control pues no era ni un burócrata profesional ni un político formado en la lucha partidaria. Hacía falta entonces un jefe político para liderar la dirección política. Con un Parlamento efectivo se solucionaría el supuesto de un monarca incompetente y, si no lo fuera, confiaría en la acción de política positiva del Parlamento.
La lucha política partidaria, en la moderna democracia de masas, fomentará la emergencia de líderes y llegarán los que tuvieren más cualidades de jefes políticos. Los líderes políticos tendrán su séquito de diputados y en la política dominará la acción de "el pequeño número de dirigentes". El Parlamento activo será el sitio de adiestramiento y selección de los políticos y allí destacarán los que tienen cualidades de líderes. Y este Parlamento será el que ejercerá la dirección política controlando a la burocracia.

Casper sintetiza como tipo ideal lo que sería una combinación entre las ideas parlamentaristas y las plebiscitarias del Weber que va entre 1917 y 1919. Se ubica así en la perspectiva de un modelo mixto. Dice: "Let me summarize so far. By 1919, Weber had developed a concept of governance in mass democracies-one might say, an ideal type-that consists of a complex mixture of descriptive and prescriptive notions. Here are what I consider the five most important elements of Weber's conception. (1) Every mass democracy tends in the direction of the caesarist model of selection: the specifically caesarist technique is the plebiscite. (2) The caesar's power derives from his charisma that responds to psychic, physical, economic, ethical, religious, or political needs and that, by its own internal logic, sets its own limits and knows no supervisory or appeals body, no technical jurisdiction. (3) The leader should have a superior intellect, rhetorical abilities, and the three qualities that Weber discusses in Politics as a Vocation: passion for a cause ("Leidenschaft im Sinne von Sachlichkeit"), a sense of responsibility ("Verantwortungsgefühl"), and a sense of proportion, the capacity to estimate, to judge ("Augenmaß").(4) As a means of checks and balances, parliamentary oversight is indispensable, especially for the protection of rights. (5) Furthermore, there needs to be a peaceful mechanism for eliminating the caesarist ruler who has made mistakes" (Casper 2007).

\section{UNA VUELTA DE TUERCA A SU DEMOCRACIA PLEBISCITARIA}

Weber, en La futura forma institucional de Alemania (Weber 1982c) ya abandona la preferencia por el parlamentarismo y piensa en alternativas institucionales. Descree del Parlamento, de la supremacía prusiana y no ve otra alternativa que la forma republicana. Reflexiona sobre el Estado unitario o el federal, y sobre el Bundesrat y la jefatura del Estado como contrapesos del poder prusiano. Respecto de la Cámara Alta piensa en un Consejo de Estados o en una Cámara Federal y en cuanto al reemplazo del Kaiser dice que tiene que ser una persona electa por el Parlamento o por el Pueblo. En definitiva, su propuesta es una República Federativa, con un presidente electo aunque sin definirse la forma de esta elección (Sell 2011). 
Weber da un paso definido respecto de su propuesta institucional de democracia plebiscitaria en 1919, en El presidente del Reich. Quería evitar la elección indirecta del presidente a través del Bundesrat, los notables y los "viejos políticos profesionales", la mala calidad que tendría un Parlamento compuesto por empleados de las corporaciones o la preeminencia de Prusia en la designación de las autoridades y funcionarios. En este sentido señala que: "Sólo un presidente del Reich apoyado por millones de votos puede disponer de la autoridad necesaria para encauzar la socialización, que no puede por cierto ser realizada mediante disposiciones legislativas, sino que depende en todo y para todo de una administración rigurosamente unitaria. Socialización significa administración" (Weber 1982a:304). Para Weber se trataba de dar al presidente suficiente poder para que la administración pudiera actuar contra las corporaciones. La representación proporcional iba a llevar a un sistema donde los distintos grupos corporativos pusieran empleados en el Parlamento actuando a través de una suerte de "voto imperativo". El Parlamento se transformaría en un "órgano corporativo" integrado por "hombres mezquinos y mediocres" perdiendo así el Parlamento su función de seleccionar a los dirigentes políticos.

Dice Weber: "el parlamento debe reconocer la carta magna de la democracia: el derecho a la elección directa del jefe" (Weber 1982a: 307). En primer lugar, entonces, la democracia debe contar con un jefe cuya fuente de legitimidad sea el propio pueblo. Pero Weber avanza mucho más en ese artículo, expresa: "un presidente electo por el pueblo que sea el jefe del poder ejecutivo, del aparato de control administrativo y que posea el derecho a un eventual veto suspensivo y el poder de disolver el parlamento, además de estar autorizado a convocar a un plebiscito, representa el baluarte de la auténtica democracia, que no significa impotente renuncia ante la confusión, sino sumisión a un jefe elegido por ella misma" (Weber 1982a:307).

Podría pensarse que la elección popular directa de un jefe-presidente, no implica mayores modificaciones de sus ideas proparlamentarias. No parece que sea así. En primer lugar el pueblo que sólo "piensa hasta pasado mañana" (Weber 1992:1116) (en el marco de sus ideas parlamentarias), aparece revalorizado en su elección del jefe. El presidente-jefe, se impone sobre el parlamento al cual puede disolver y comanda la burocracia. Está ubicado en la cúspide del poder. El cuadro de este nuevo esquema de gobierno sería: la legitimidad del sistema ubicada en el Presidente elegido directamente por las masas; su eficacia en el poder que reviste y que le otorga el apoyo popular, y en la conducción suprema de la burocracia; la estabilidad garantizada a través del presidente que no necesita el acuerdo de los partidos ni del Parlamento $\mathrm{y}$, por tanto, no le afectarían las rupturas de coalicio- nes partidarias. Los actores políticos principales que tejen el juego institucional son: el jefe y las masas; los actores políticos relegados: el Parlamento que debe perder poder y la burocracia que debe ser comandada por el jefe; y el actor político temido: el partido político. Si el parlamentarismo era un esquema que atenuaría el peligro del "fuerte predominio en la política de los elementos emocionales" (Weber 1992:1116), la forma plebiscitaria llamada "auténtica democracia" contendrá fuertes elementos "emotivos".

No se trata por lo tanto de un esquema mixto, sino de dos arquitecturas distintas -sobre todo si consideramos el texto de El Presidente del Reich-, conformadas, eso sí, con las mismas piezas (por ejemplo, en el modelo plebiscitario no desaparecen ni el Parlamento ni los partidos políticos). Y a ese cuadro debería añadirse las consideraciones del autor sobre determinados atributos de la dominación carismática -vistos anteriormente- sobre los cuadros administrativos y la justicia.

El planteo de democracia plebiscitaria que hará finalmente Weber tiene como destinario a Alemania y esto por su especial situación. En primer lugar, la tradición política de un Parlamento prácticamente inexistente y una burocracia muy profesionalizada, en segundo lugar la situación de crisis y el contexto de emergencia que implicó la Gran Guerra y la necesidad de un nuevo orden político para Alemania, y en tercer lugar lo que cabría esperar del estado en que partiría la reconstrucción política alemana: ausencia de políticos profesionales de vocación, probable dictadura del "populacho", parlamento dócil e ineficiente para la selección de los dirigentes, partidos políticos representantes del viejo orden. Ante tal contexto, ni el gobierno colegiado ni el jefe elegido por el Parlamento eran salidas viables para recuperar la economía alemana y construir una "democracia progresista (económica y política)". La conjunción presidente-masas sería un contrapeso a la primacía de los notables y a un probable Parlamento corporativo. La presidencia serviría como base de unidad del Reich contra las tendencias particularistas (Weber 1982a: 303-307). Base política fuerte y estable que requeriría, además, la colaboración comprometida de los empresarios y la burguesía económica.

\section{Coherencias en el pensamiento DE WEBER: LA IMPORTANCIA DEL LÍDER}

Más allá de los condicionantes históricos vale la pena profundizar en el pensamiento de Weber, y ver si existían en sus ideas elementos facilitadores de ese paso. En primer lugar, si uno observa el elemento que aparece sin cuestionamientos en los dos esquemas de democracia, este es la importancia del líder (Sell 2011). A tal punto es así que constituye el elemento central el modo en que este líder es elegido: por selección parlamentaria o por decisión popu- 
lar. En el llamado proceso de "democratización" la mayor o menor participación de los ciudadanos no es lo fundamental. Dice Weber: "El demos, en el sentido de una masa inarticulada, no gobierna nunca en las sociedades numerosas por sí mismo, sino que es gobernado, cambiando sólo la forma de selección de los jefes del gobierno y la proporción de la influencia que puede ejercer 0 , mejor dicho, que pueden ejercer otros círculos procedentes de su seno, por medio del complemento de una llamada opinión pública, sobre el contenido y la dirección de la actividad de gobierno...democratización no debe significar necesariamente el aumento de la participación activa de los dominados en el dominio dentro de la organización considerada. Esto puede ser la consecuencia del proceso aquí señalado, pero puede no presentarse. Más bien hay que tener muy en cuenta que el concepto político de la democracia deduce de la igualdad jurídica de los dominados estos otros dos postulados: 1) trabas al desarrollo de un estamento de funcionarios cerrado en favor de la accesibilidad general a los cargos, y 2) reducción a lo mínimo de su poder en interés de la mayor amplitud posible de la influencia ejercida por la opinión pública... Lo decisivo es... la nivelación de los grupos dominados con respecto a los grupos dominadores burocráticamente articulados, los cuales pueden poseer por su lado de hecho, y con frecuencia también formalmente, una estructura del todo autocrática" (Weber 1992:739),

Para Weber en política y, cualquiera que sea la forma de gobierno, rige siempre la ley del gobierno del "pequeño número". En este sentido, se acerca a los autores de la teoría de las élites, como Michels, Mosca y Pareto. Si el sistema parlamentario no garantiza la selección de un verdadero líder, la opción debe ser la elección popular directa. Es que en el autor aparece menos una justificación filosófica de la democracia, que la opción en base a su mayor eficacia en conexión con la selección de los líderes ${ }^{2}$. Por otra parte, para Weber, la democracia en sí misma implicaba la emergencia del "aparato" de partido y, con éste, la democracia no podía sino ser plebiscitaria; pero contra la demagogia resultante un Parlamento efectivo -teóricamente- atenuaría sus perniciosos efectos, como ocurría en el caso de Inglaterra.

La otra cuestión que no debe perderse de vista y que resulta significativa es que la clave de la democratización no es tanto la mayor participación del pueblo o "incremento de la participación activa de los dominados", sino las trabas para que no se enquiste un estamento de funcionarios y se abra la accesibilidad a los cargos y el incremento de la igualdad jurídica de los dominados. Weber se aleja aquí de las formas o procedimientos de la democracia -en su versión participativa- y parece atender a los resultados -la nivelación de los grupos dominados respecto de los dominadores- para calificar a un régimen como más democrático.
En segundo lugar, más allá de que Weber fuera tan categórico sobre la propuesta plebiscitaria en el trabajo, El presidente del Reich, contra las ventajas que supondría el sistema parlamentario había dado también pautas sobre aspectos no desestimables de la elección plebiscitaria, o bien que matizaban sus reparos sobre este tipo: a) en conjunto, con la elección popular del jefe de Estado en los Estados Unidos no se hicieron malas experiencias (Weber 1992:1112); b) la elección plebiscitaria en algunos casos era eficaz remedio contra la corrupción (Weber 1992:1110); c) el jefe plebiscitado podía ser un buen principio para la emergencia de nuevos partidos; d) la burocracia no puede ser controlada por un Parlamento negativo; o un autócrata, en cambio, en ciertas ocasiones es más eficaz un Monarca (Jefe) con apoyo popular (Weber 1972a:218); e) el liderazgo carismático era el requisito de la auténtica jefatura política (Weber 1980a:120). Asimismo, las grandes decisiones políticas -sobre todo en democracia- fueron hechas por el individuo, lo que justificaba "fuertes concesiones al principio cesarístico de la selección de jefes" (Weber 1992:1110). Y señala que, "siempre que se han enfrentado a grandes problemas, los partidos democráticos de masas han debido someterse por doquier más o menos incondicionalmente a jefes que poseyeron la confianza de las masas" (Weber 1992:1110).

Por otro lado, los tipos puros de dominación no acostumbran a darse en la realidad (Weber 1992:173), sino más bien en forma mixta y, en relación al liderazgo carismático Weber observó que se daba en todo tiempo y lugar. Por otra parte, el tipo plebiscitario no va en contra de lo que implica en esencia el proceso de democratización, en este sentido, tiene relevancia: la apertura del estamento de los funcionarios en favor de la accesibilidad general a los cargos y la mayor influencia de la opinión pública en la dirección del gobierno. Y podría, en ciertos casos, reconducir procesos teñidos de mera demagogia y de primacía de la burocracia (en un proceso de mayor burocratización). Existían por lo tanto elementos como para sostener que el paso de la democracia parlamentaria a la plebiscitaria, si bien obedeció a la variación de la situación política alemana, se vio facilitado por las propias ideas de Weber. Pero este paso significaba quizá cierta tensión con partes de su pensamiento.

\section{EN EL LIDERAZGO CARISMÁTICO SE LOCALIZA LA TENSIÓN MÁXIMA DE LA PROPUESTA PLEBISCITARIA}

Aclarando que la primera preferencia de Weber era sobre la monarquía parlamentaria, cabe señalar que su propuesta plebiscitaria implicaba una tensión quizá no tan evidente. Al asumir el presidente-jefe el liderazgo político efectivo, en cierta forma desaparece el "carisma rutinizado" con la eliminación (o 
inexistencia) de una monarquía o de una jefatura estatal alternativa y simbólica. Los problemas de esta opción serían al menos cuatro, los límites del jefe, su emergencia, mantenimiento y sucesión.

1. Respecto de los límites del poder de un jefe que emerge del voto popular. Es cierto que propone controlar su poder, pero su apelación no parece suficiente. Weber debe recurrir a una contención que presenta los límites de la construcción imprecisa y sin mayores desarrollos. Dice que al intento del presidente de gobernar como un autócrata debe oponerse el "riesgo constante de ser políticamente ajusticiado", (Weber 1982a:304);

2. La emergencia de un jefe que sintonice con el pueblo y que tenga verdaderos atributos para el poder no ocurre siempre, menos aún el genio y "pueden darse largos períodos en los que faltan hombres que gocen de la confianza general de las masas" (Weber 1992:1114). La existencia de un presidente plebiscitado no garantiza la aparición del líder político carismático, por tal razón era también importante el Parlamento -en su modelo parlamentariopara llenar ese probable vacío.

3. Queda sin resolver el problema del mantenimiento del jefe en el poder que se resolvía en el parlamentarismo a través del "carisma rutinizado" en manos del monarca y de una jefatura de gobierno sobre la cual recae la "prueba del liderazgo"; el jefe presidente -con verdadero poder- para seguir siéndolo, debe "probar" su eficacia y sus dotes superiores (Weber 1972b:256-259).

4. La existencia de un Monarca parlamentario implica que "la posición suprema del Estado está definitivamente ocupada" y esto tiene efectos políticos importantes; entre otros, el de limitar el ansia de poder de los políticos y la existencia de una figura (el Monarca) de influencia moderadora.

5. Por último, estaría el problema de la sucesión del jefe cesarístico. Dice Weber: "El problema de la sucesión ha constituido por doquiera el talón de Aquiles del gobierno puramente cesarístico" (Weber 1992: 1114).

Estos puntos relacionados con la emergencia y continuidad (mantenimiento y sucesión) del liderazgo carismático eran los que marcaban la mayor distancia en el pensamiento de Weber entre los dos esquemas democráticos. Y, por qué no, la propia imposibilidad de una democracia plebiscitaria (presidencial) duradera, en cuanto a la estabilidad política misma, más allá del líder plebiscitario. No es, entonces, del lado de la eficacia donde se encuentra la tensión más importante entre los diferentes esquemas democráticos -aunque existe, sobre todo res- pecto de la racionalidad económica-, sino en cuanto a los efectos en torno a la estabilidad política que podrían derivarse de ambas formas institucionales.

\section{LA DEMOCRACIA PLEBISCITARIA Y ALGUNOS CRUCES TEÓRICOS}

La influencia de Weber ha sido notoria, por ejemplo su "teoría de la acción" en las obras de Talcott Parsons, la escuela de Rational Choice y Jurgen Habermas (Abellán 2010). Lo tratado en este trabajo resulta esencial para otros debates actuales. La rica densidad de su pensamiento se revela aún más cuando a la democracia presidencial y al modo plebiscitario de elección directa del jefe le agregamos los contenidos propios de la dominación carismática. Así, desde el propio Weber podemos despegarnos del Weber que realiza las propuestas. Una democracia presidencial que implica el modo plebiscitario de elección directa del jefe en un formato de república presenta fuertes atributos de dominación carismática que coexisten con elementos de dominación legal-burocrática, y que le impone determinadas características, tanto al régimen (democrático) como a la forma de gobierno (presidencial). Es probable que tenga algunas o varias de las siguientes características. Se encaminará hacia una democracia personalista, donde el presidente es el único que se ha sometido al voto de toda la población y ha triunfado, según las reglas de la democracia. Por esto sentirá -él y la población- que tiene una legitimidad democrática superior al resto. El parlamento tendrá una presencia secundaria y la justicia intentará ser controlada por el presidente y tendrá una pobre cualificación. Al fin de cuentas, quien puede arrogarse la legitimidad de todo el pueblo es el líder elegido. La auténtica democracia "es la elección del jefe". La división de poderes y, sobre todo, el mecanismo de checks and balances pueden estar muy diluidos o llegar a ser prácticamente inexistentes. La administración y la Justicia se conformarán con personal amigo, de confianza o seguidores del presidente. En tanto y en cuanto el carisma sea probado (o se mantenga) este presidente podrá actuar unilateralmente -por ejemplo a través de decretos- y será difícil el ejercicio de una rendición de cuentas horizontal pues las instituciones están controladas o subordinadas al presidente. Pero cuando la evidencia o la prueba muestren el desvanecimiento del carisma, los seguidores desertarán y la estabilidad estará en jaque pudiéndose ejercitar una suerte de rendición de cuentas vertical. Problemas de legitimidad y estabilidad probablemente ocurrirán con el talón de Aquiles de las formas carismáticas: la sucesión.

Esta breve descripción de la democracia presidencial plebiscitaria en formato de república, en distintas intensidades y matices se ha extendido empíricamente en el espacio. La actualidad de los desarrollos de Weber es notoria en cuestiones tales como el 
liderazgo, la gobernabilidad y las instituciones (Sell 2010). Asimismo, se cruzan con distintas cuestiones y perspectivas teóricas, entre otras: 1) el tipo de democracia; 2) el régimen presidencial; c) el populismo.

Respecto del tipo de democracia, varios autores señalan que existe en la actualidad una cantidad de países con democracias electorales que, sin embargo, no respetan los límites constitucionales, la división de poderes y las libertades. La democracia crece, pero el constitucionalismo liberal disminuye y el ejercicio del poder está más concentrado en el líder gubernamental. Merkel (2004) habla de democracias defectuosas donde existe ausencia o vicios de algunos elementos como el Estado de Derecho, división de poderes y el control horizontal. Estas democracias defectuosas tendrían varios subtipos, entre otros las iliberales y las delegativas. Zakaria (1997) ha destacado el fenómeno de las democracias iliberales. Señala que las democracias liberales occidentales del siglo $X X$ se caracterizaron por la existencia de un Estado de Derecho, la división de poderes, la protección de las libertades de expresión, religión, reunión y propiedad. Pero a finales de siglo estos atributos se fueron desdibujando y destaca, entre otros aspectos relevantes (para América Latina y la ex Unión Soviética), la emergencia de fuertes líderes presidenciales que se dirigen directamente al pueblo evitando las mediaciones institucionales y en un marco de desequilibro de poderes. Wolff (2013) destaca que en las llamadas democracias post-liberales una característica es el carácter más plebiscitario del gobierno y el reforzamiento del líder presidencial. La democracia delegativa planteada por O'Donnell (1992) describía algunas experiencias latinoamericanas de los noventa y planteaba sus trazos menos liberales y menos republicanos, donde el pueblo delegaba sus decisiones en un líder que encarnaba la Nación. En su revisión, dos décadas después, O’Donnell (2010) agregaba el marco hiperpresidencialista y un mayor espesor del líder delegativo. Este líder es el presidente que se constituye en la persona de "confianza" del pueblo y al que se le delega todo el poder a través del acto plebiscitario. Avanza sobre las competencias del Legislativo y la Justicia y el ejercicio de la rendición de cuentas horizontal se convierte en una tarea dificultosa.

Respecto del régimen presidencial, el clásico trabajo de Linz (1994) acerca del presidencialismo latinoamericano refería expresa o implícitamente a Weber. Decía que había sido el primero en formular el Ejecutivo bicéfalo que se 'plasmó en la Constitución de Weimar y décadas después en la $V$ República francesa (y en otros países). No sólo Linz exploraba el presidencialismo como sistema, sino que analizaba la figura y el papel del presidente, evocando implícitamente a Weber. En su estudio aparece la importancia del acto plebiscitario, la "misión" que suele portar el presidente y el hecho de que es investido de especiales cualidades por la población. Destacaba, fundamentalmente, los problemas de estabilidad institucional y también la dificultad del ejercicio de la accountability horizontal. Esta presencia del líder plebiscitario excede el marco del sistema presidencial. Weber ya lo advertía cuando decía -en La política como profesión- que dentro del propio sistema parlamentario inglés se había producido un cambio en los partidos y el juego del parlamento mostraba la emergencia de líderes plebiscitarios. No parece casual que en los últimos años se haya instalado un debate sobre la "presidencialización del parlamentarismo". Fabbrini (2009) en El ascenso del Príncipe democrático señala que en la Europa de nuestros días -y a partir de la década del ochenta- frente a la democracia de partido se ha erigido la democracia de líderes en países como Italia, Francia y Gran Bretaña. Es que el líder plebiscitario instalado en el Ejecutivo parece perforar todos los sistemas institucionales. Agamben (2004) dio cuenta también de que el Poder Ejecutivo, en Occidente y en el transcurso del siglo $X X$, ha ocupado el centro de la escena política habiéndose pasado de la República Parlamentaria a la República Gubernativa.

Respecto del populismo y más allá de todas sus ambigüedades y equívocos, tiene en su centro la figura de un líder, el pueblo (en una variedad de acepciones) e instituciones esquivas del liberalismo institucional. Laclau $(2004,2006)$ articuló una perspectiva compleja que desde los estudios de Le Bon hilvanaba la Psicología de las masas de Freud con los desarrollos lacanianos para explicar el fenómeno populista. La dicotomización del espacio social produce la ruptura populista cuando la equivalencia de las demandas insatisfechas cristaliza en torno de ciertos símbolos comunes y, fundamentalmente, en la emergencia de un líder. Este líder encarna el proceso de identificación popular y es el elemento aglutinante, incluso en procesos no considerados por la literatura como populistas. En Weber aparece claramente la dominación carismática como una "ruptura", teniendo un carácter revolucionario o utópico, que se distancia de la dominación tradicional y la burocrático-legal pues ambas intentan mantener un statu quo. Si bien fue Freud quien introdujo como pieza clave el proceso de "identificación" de la masa con el líder, fue Weber quien, antes, le dio localización política a este fenómeno dentro de las características de la dominación carismática.

\section{A MODO DE REFLEXIÓN FINAL}

La democracia plebiscitaria aparece en los textos referidos desde dos perspectivas o posiciones. Una científica y, la otra, proponiendo una alternativa política, aunque no es fácil distinguir siempre al Weber político y al científico en sus escritos políticos (Eliaeson 1991: 318) Como científico Weber desarrolló el concepto de democracia plebiscitaria o de caudillos, 
de acuerdo a un análisis histórico, político y sociológico. Como propuesta política fue una alternativa brindada para un momento histórico determinado que vivía Alemania.

Es claro que la democracia plebiscitaria de El presidente del Reich, no emerge de la investigación científica de Weber. Su indagación académica reflejó la tendencia plebiscitaria de la democracia de masas y una serie de características que tuvieron las formas plebiscitarias a través del tiempo y que no parece que Weber las valore positivamente. Pero es todo un síntoma que el autor, con su conocimiento del cesarismo o del liderazgo plebiscitario, haya considerado que, en determinados momentos, pueda ser una forma válida para superar un momento de crisis. Ahora bien, se vio que este paso - de la democracia parlamentaria a la plebiscitaria- motivado por cuestiones singulares podía darse sin conculcar totalmente un aspecto central en su pensamiento: el papel fundamental del líder político. Aquí también se encontraba cierta tensión respecto de su sociología de la autoridad carismática.

Sobre la adhesión de Weber a la democracia no puede haber dudas, tanto por su vida personal como por sus escritos (Abellán 2004: 203). Lo que puede decirse es que no tuvo una visión ingenua de la democracia. Sabía que primaría el "pequeño número", que no necesariamente implicaba mayor participación y democracia significaba también burocratización. Pero también implicaba la elección libre de los gobernantes y la mayor igualación de la población en el acceso a las posiciones burocráticas y de gobierno. Pero si vamos más allá de lo escrito por Weber, utilizando sus categorías y reflexiones puede soste- nerse que la democracia presidencialista plebiscitaria adquiere otra dimensión.

En el formato de República presidencialista el cargo más importante es el de presidente y sobre el cual gira todo el sistema pues es el "jefe" político. Su emergencia se debe a una selección plebiscitaria que, si bien existe también en la selección de los líderes del sistema parlamentario, es mucho más extensa e intensa. Extensa por el respaldo directo de los "millones de votos" que señalaba Weber como soporte para comandar la burocracia y no necesitar de coaliciones parlamentarias. Y esta república presidencialista plebiscitaria se enmarca en la dominación carismática que es especialmente intensa pues es personal y más emotiva.

Frente a este cuadro, resulta al menos difícil -aunque no imposible- que el Parlamento pueda obrar siempre como necesario contrapeso del poder que adquiere el presidente. Tampoco resulta sencillo que si el presidente intenta gobernar como un autócrata pueda oponerse el "riesgo constante de ser políticamente ajusticiado". Y el marco fuerte de dominación carismática significa la alta probabilidad de que la administración y la justicia sean integradas por seguidores o amigos del jefe presidente y funcione más allá de reglas formales o abstractas. Esto, cabe remarcar, no lo dice Weber expresamente cuando formula su opción presidencial, pero es legítimo pensar que es una opción factible -y hasta bastante probable- según los elementos referidos (república presidencial, selección plebiscitaria y marco de dominación carismática). El cruce con debates actuales referidos no es más que una prueba palpable de la importancia de Weber para entender los derroteros de la democracia en estos tiempos.

\section{NOTAS}

1. En este sentido apunta la interpretación de Juan Carlos Portantiero (1983).

\section{RefEREnCIAS Bibliográficas}

Abellán, J. 1992. "El pensamiento político de Weber". Pp. 440468 en Historia de la Teoría Política (Tomo 4), editado por F. Vallespín. Madrid: Alianza.

Abellán, J. 2004. Poder y política en Max Weber. Madrid: Biblioteca Nueva.

Abellán, J. 2010. "Estudios preliminar" Pp. 9-61 en Max Weber. Conceptos sociológicos fundamentales, editado por J. Abellán. Madrid: Alianza.

Agamben, G. 2004. Estado de excepción. Buenos Aires: Hidalgo.

Aron, R. 1965. La sociología alemana contemporánea (2ed.). Buenos Aires: Paidós.

Bernhard, M. 1998. "Charismatic Leadership and Democratization: A Weberian Perspective”. Disponible en: https:// www.ucis.pitt.edu/nceeer/1998-812-20g-Bernhard.pdf [Consulta 23 septiembre 2015].

Breuer, S. 1996. Burocracia y Carisma. La Sociología Política de Max Weber. Valencia: Edicions Alfons El Magnanim.
2. Ver al respecto las interesantes apreciaciones de Joaquín Abellán (1992:440-468).

Casper, G. 2007. "Caesarism in Democratic Politics- Reflections on Max Weber". Library of Congress. Disponible en: https://www.loc.gov/today/cyberlc/feature_wdesc. php?rec=4035 [Consulta 10 de mayo de 2015].

Eliaeson, S. 1991, "Between Ratio and Charisma. Max Weber's views on plebiscitary leadership democracy". Statsvetenskaplig Tidskrift 4: 317-339. Disponible en: http://journals.lub.lu.se/index.php/st/article/download/2892/2456 [Consulta 30 de mayo de 2015].

Fabbrini, S. (2009). El ascenso del Príncipe democrático. Quién gobierna y como se gobiernan las democracias. Buenos Aires: Fondo de Cultura Económica.

Gerth, H. H. y C. Wright Mills. 1991. From Max Weber: Essays in Sociology. London: Routledge.

Gramsci, A. 1993. La política y el Estado moderno. Barcelona: Planeta-Agostini.

Lachmann, L. M. 1970. The Legacy of Max Weber. London: Heinemann. 
Linz, J. J. 1994. "Presidential or Parliamentary Democracy: Does It Make a Difference?". Pp. 3-87 en The Failure of Presidential Democracy (vol. 1), editado por J. J. Linz y A. Valenzuela. Maryland: The Johns Hopkins University Press.

Laclau, E. 2004. La razón populista. Buenos Aires: Fondo de Cultura Económica.

Laclau, E. 2006. "La deriva populista y la centroizquierda Latinoamericana”. Nueva Sociedad 205: 56-61.

Lowenstein, K. 1982. Teoría de la Constitución. Barcelona: Ariel.

Merkel, W. 2004. "Embedded and Defective Democracies". Democratization 11(5): 33-58.

Mommsen, W. 2014. "Sobre el surgimiento de la obra póstuma de Max Weber. Economía y Sociedad". Estudios Sociológicos XXXII 96:709-766.

O’Donnell, G. 1992. “¿La democracia delegativa?”. Cuadernos del CLAEH 1: 5-20,

O'Donnell, G. 2010. "Revisando la democracia delegativa". Casa del Tiempo 31: 2-8.

Portantiero, J. C. 1983. Los usos de Gramsci. México: Folios.

Sell, C. 2010. "Max Weber: democracia parlamentar ou plebiscitária?". Revista de Sociologia e Política 18(37): 137-147.

Sell, C. 2011. "Democracia com liderança. Max Weber e o conceito de democracia plebiscitária". Revista Brasileira de Ciência Política 5: 139-166.
Weber, M. 1972a. Ensayos de sociología contemporánea (Tomo I). Barcelona: Planeta.

Weber, M. 1972b. Ensayos de sociología contemporánea (Tomo II). Barcelona: Planeta.

Weber, M. 1980a. "La política como profesión". Pp. 63-143 en Max Weber: Ciencia y Política. Buenos Aires: CEAL.

Weber, M. 1980b. "La ciencia como profesión". Pp. 21-62 en Max Weber: Ciencia y Política. Buenos Aires: CEAL.

Weber, M. 1982a. "El presidente del Reich". Pp. 303-307 en Escritos Políticos. Tomo II. México: Folios.

Weber, M. 1982b. "Parlamento y gobierno en el nuevo ordenamiento alemán". Pp. 59-162 en Escritos Políticos. Tomo I. México: Folios.

Weber, M. (1982c). "La futura forma institucional de Alemania". Pp. 253-293 en Escritos Políticos (Tomo II). México: Folios.

Weber, M. 1992. Economía y Sociedad. Buenos Aires: Fondo de Cultura Económica.

Wolff, J. 2013. "Towards Post-Liberal Democracy in LatinAmerica? A Conceptual Framework Applied to Bolivia". Journal of Latin American Studies 45: 31-59.

Zakaria, F. 1997. "The Rise of Illiberal Democracy". Foreign Affairs 76(6): 22-43.

MARIO D. SERRAFERO es Doctor en Ciencias Políticas y Sociología, Universidad Complutense - Instituto Universitario Ortega y Gasset. Doctor en Derecho Público, Universidad de Buenos Aires. Licenciado en Psicología y en Derecho, Universidad de Buenos Aires. Diploma de Especialización en Sociología Jurídica, Universidad de Buenos Aires. Investigador Principal del Consejo Nacional de Investigaciones Científicas y Técnicas (CONICET) en el Instituto de Investigaciones Gino Germani. Catedrático de la Universidad de Buenos Aires. Miembro de Número y Director del Instituto de Filosofía Política de la Academia Nacional de Ciencias Morales y Políticas. 